\title{
Alfabetização: desafios da prática alfabetizadora
}

\author{
Literacy: the challenges of its practice
}

\author{
Jacqueline de Fátima dos Santos MORAIS \\ Mairce da Silva ARAÚJO
}

\begin{abstract}
RESUMO
Apesar de importantes pesquisas serem divulgadas nas últimas décadas sobre os múltiplos aspectos que contribuem para a produção do fracasso escolar na alfabetização, vimos reacender, recentemente, a defesa de que este problema relaciona-se fundamentalmente aos métodos utilizados pelas professoras. Dialogando com Freire e Morin, entre outros autores, continuamos a defender, no presente artigo, que precisamos ver com olhos menos reducionistas a alfabetização. Em nossas reflexões sobre a vivência cotidiana no mundo da escola, temos percebido que as aproximações entre o legado de Paulo Freire e a epistemologia da complexidade podem apontar novas pistas para a construção de práticas alfabetizadoras emancipatórias. Práticas que potencializem professores e professoras, alunos e alunas, a escreverem e dizerem suas próprias palavras, especialmente, em contextos históricos de exclusão e negação das diferenças culturais, como na sociedade brasileira. Trazendo situações do campo da pesquisa, o trabalho enfoca a multiplicidade de experiências com a linguagem escrita, que acontecem no cotidiano da escola, desvelando os ambientes alfabetizadores múltiplos e híbridos que compõem o cotidiano escolar. O desafio que hoje temos na escola é o de ver a leitura como algo mais que apenas soletrar a escrita, e vermos na escrita algo mais que a transcrição da fala. É preciso que nós, professores e professoras, nos apropriemos de referenciais teóricos que nos ajudem a olhar e ver de forma ampliada o processo de alfabetização. Não se trata de propor à professora um novo método de alfabetização, porém, trata-se de enfatizar a importância da reflexão coletiva e do permanente se prepara como condições básicas para o fortalecimento de uma prática alfabetizadora comprometida com as crianças das classes populares.
\end{abstract}

Palavras-chave: alfabetização, cotidiano escolar, formação de professores. 


\begin{abstract}
In spite of the important researches made known in the last decades about the multiple aspects which contribute to the production of school failure in literacy, we have seen recently to be brought to light the connection of this problem to the teaching methods used by teachers. Based on a dialogue with Freire and Morin among others, we continue in this article, our defense of an urge to see literacy through less reducing point of view. In our reflections about the daily life in the school's world we have noticed that the approach between Paulo Freire's legacy and the epistemology of complexity may point out new clues to the construction of emancipating literacy practices. Such practices do bring power not only to teachers-to-be, but also to learners, as they write and express themselves, especially in historical contexts of exclusion and the denial of cultural differences in the Brazilian society. This work focuses, through situations of field research, on the multiplicity of experiences with the written language, which happen on the school's daily life, revealing the hybrid and multiple literacy environments which are part of that daily life. The challenge we face at school nowadays is that of seeing the reading as more than a mere act of spelling, and seeing writing further than a speech transcript. We, teachers, have to take hold of theoretical references which help us look at and see the process of literacy from its broadest sense. It does not mean that we should propose to teachers a new literacy method, but focus on the importance of a collective reflection and on the permanent "get ready" as basic conditions for the strengthening of a literacy practice compromised with the working-class children.
\end{abstract}

Index Terms: formation of teachers, literacy, school's daily life.

\title{
1 Alfabetização: sempre uma questão política
}

Entre os desafios que a escola pública continua a enfrentar no Brasil, a alfabetização das crianças das classes populares permanece destacando-se como algo que não se resolveu completamente. A alfabetização representa, sem dúvida, uma das questões sociais fundamentais em sociedades letradas, especialmente por suas implicações político-econômicas.

Hoje, embora os dados do Ministério da Educação e Cultura (MEC) apontem a quase universalização da educação básica na sociedade brasileira, os altos índices de fracasso escolar, principalmente na alfabetização, 
continuam revelando a face perversa do sistema educativo: recebe a quase todos, mas não é capaz de ensiná-los. A democratização do acesso à escola — são cerca de 55 milhões de matrículas nas quase 218 mil escolas distribuídas em 5.560 municípios brasileiros segundo dados do senso escolar de 2001 - não representou uma real democratização do acesso ao saber e a cultura letrada.

A entrada da quase totalidade dos alunos nas classes de alfabetização não tem significado ainda a permanência deste contingente na escola. Segundo dados do estudo Geografia da Educação Brasileira 2001, divulgado somente em 2003 pelo Inep ${ }^{1}$, do total de alunos que ingressam na série inicial do Ensino Fundamental $60 \%$ não concluem o ensino médio. De cada 100 crianças que entram na $1^{\mathrm{a}}$ série do Ensino Fundamental 41 não terminam a $8^{\mathrm{a}}$ série. Outro importante dado diz respeito à distorção série/ idade. O mesmo estudo do Instituto Nacional de Estudos e Pesquisa Educacionais (Inep) mostra que 39\% dos alunos matriculados têm idade superior àquela esperada como regular na série que está.

A interdição que, especialmente, as classes populares vivem ao processo de apropriação da leitura e da escrita encontra terreno em múltiplos aspectos internos e externos à escola: a falta de uma política educacional que garanta uma escola de qualidade, as más condições físicas e de segurança das escolas; a falta de professores, a falta de bibliotecas não só as escolares, como públicas nas cidades; as dificuldades de aquisição por parte da população de livros, jornais, revistas; o não-acesso à informática...

Viver o processo de interdição não significa, porém, que as classes populares o aceitem passivamente. Pelo contrário, a História do Brasil é rica em exemplos que apontam as formas de resistência encontradas pela população em sua busca pelo direito ao saber. Oliveira (1992) lista alguns

\footnotetext{
${ }^{1}$ Sinopse Estatística da Educação Básica: censo escolar. Instituto Nacional de Estudos e Pesquisa Educacionais. Brasília, Inep, 2001
} 
movimentos de luta, deixando claro que os embates pela educação de qualidade para todos não se constitui como uma bandeira recente, mas representa uma luta histórica: desde as associações de operárias do século XIX, passando pelas escolas anarquistas do início do século XX, por toda a riqueza dos movimentos de cultura popular e de educação de base nos anos de 1950 e 1960 e, mais recentemente, pelo movimento das escolas comunitárias que se espalhou por várias regiões do Brasil.

Além disso, as filas à porta das escolas públicas, onde especialmente as mães varam as madrugadas, na tentativa de garantir uma vaga para seus filhos ou filhas, também representam formas de resistência e luta do povo pela educação de seus filhos. A formação de filas em muitas das escolas públicas brasileiras, mostra que apesar de todo o discurso sobre a falência do ensino público, a população acredita neste espaço e investe em suas possibilidades. Não é sem razão que na educação básica $87 \%$ dos alunos estão matriculados em escolas pertencentes à rede pública de ensino, segundo o MEC. Esta é uma das provas de que as classes populares possuem o que Marília Spósito chama de ilusão fecunda. No dizer de Garcia esta ilusão é fecunda, pois:

[...] embora nada garanta que a escolaridade seja caminho certo para a melhoria de vida, a luta coletiva pelo direito à escola, entre outros direitos historicamente negados, potencializa as classes populares para a conquista de uma cidadania ativa, para a autonomia, indicando avanços no sentido da democratização da sociedade. (GARCIA, 2000, p. 12)

A aposta que as famílias fazem na educação de seus filhos mostra que a escola é vista como lugar de potencialização e não apenas, como querem alguns, lugar de discriminação e exclusão. Neste sentido poderíamos nos perguntar: a quem interessa que a escola seja vista apenas como lugar de produção de fracasso escolar? 


\section{De volta à questão: por onde devo seguir?}

Apesar de tantas discussões sobre os múltiplos aspectos que contribuem para a produção do fracasso escolar na alfabetização, a idéia fortemente apregoada é de que este problema relaciona-se fundamentalmente aos métodos utilizados pelos professores. A ação docente deveria pautar-se, nesta perspectiva, na busca pelo método de melhor eficiência. A questão da alfabetização se reduziria, assim, a uma única questão: a do método.

A polêmica, durante bom tempo, tanto no meio acadêmico quanto nas escolas, reduziu-se a discutir se os métodos sintéticos seriam melhores que os métodos analíticos, sendo os primeiros aqueles que partem de unidades menores como letras ou sílabas, e os segundos que partem da palavra ou unidades maiores que ela. Alimentando-se desta polêmica, podemos encontrar autores de cartilhas e donos de editoras, que asseguram, na venda desse tipo de material, boas somas de dinheiro, pois que a venda de cartilhas ainda constitui-se como um grande filão no mercado editorial.

Mais recentemente, a defesa pelo retorno do método fônico às salas de aula reacendeu a centralidade da discussão metodológica no processo de alfabetização.

São visíveis as consequiências de um trabalho alfabetizador voltado para a apropriação de um modelo textual tão pobre, como o que encontramos nas cartilhas tradicionais. Produções do tipo: “A mamãe é boa. A mamãe é bonita. A mamãe come bolo.”, tão comuns nos cadernos e livros didáticos das crianças em fase de alfabetização, revelam que os alunos e alunas aprendem na escola que escrever não é registrar suas histórias, pensamentos ou desejos. Escrever é reproduzir a idéia de outro: aqui, a da autora da cartilha usada em sala de aula. 
Se as escritas dos nossos alunos revelam a pobre qualidade do processo alfabetizador vivido por eles, então, por que ainda vemos sua utilização de maneira hegemônica nas escolas?

Uma pesquisa realizada pelo Centro de Alfabetização, Leitura e Escrita (Ceale), em 2001, apontou que professores têm optado pelas cartilhas menos recomendadas pelo Plano Nacional do Livro Didático. O que esta opção das professoras significa? Por que parecem escolher justamente os livros didáticos que são apontados como os que possuem menor qualidade? E mais: o que ainda nos move a crer que é o método de alfabetização - inúmeras vezes traduzido como a melhor cartilha - o responsável pela eficiência da aprendizagem da leitura e da escrita?

Meninos e meninas não se acham mergulhados em um mundo ágrafo, mas vivem em uma sociedade na qual tantas formas de escrita que não apenas os textos de cartilhas - circulam. Meninos e meninas esbarram em seu cotidiano com variados objetos de leitura, múltiplos em conteúdos e formas, tomando-os como objeto de reflexão, como não poderia deixar de ser, posto que a curiosidade na criança é força que impulsiona para a vida e para a descoberta. Consideremos também que para muitos desses meninos e meninas refletir sobre os objetos de leitura faz parte da luta diária pela sobrevivência. É pensando sobre esses objetos textuais que meninos e meninas, de todas as raças e credos, cores e cultura, elaboram e reelaboram explicações para si e para o outro sobre como funciona a escrita. As crianças vivem na vida cotidiana movimentos onde ora confirmam ora põem em jogo os conhecimentos que produzem sobre a escrita, confrontando-os com outros saberes encontrados ao redor. Vão assim se aproximando das formas e usos que este sistema de representação possui em seu tempo e lugar. As crianças, assim, criam e recriam formas de ler e entender o escrito, pois que estão em processo de permanente (re)construção de conhecimento. E tudo isso ocorre, é preciso que tenhamos clareza, para 
além do ensinado na escola, para além do aprendido com as professoras, para além dos métodos definidos pela escola.

Tanto os métodos sintéticos quanto os métodos analíticos partem, mesmo que disso não tenhamos clareza, do pressuposto de que inicialmente a aprendizagem da lecto-escritura é uma atividade mecânica, pois trata-se apenas da aquisição de uma técnica. Ler e escrever, portanto, são vistos como ensináveis porque passíveis de treino. Também a escrita, em ambas concepções (sintética e analítica), é entendida como apenas uma transcrição gráfica da oralidade. O problema é que não encontramos em língua alguma um sistema que seja uma correspondência perfeita entre som e grafema, ou seja, que possua uma relação biunívoca entre o oral e o escrito.

Para pensarmos outra maneira de entender a alfabetização é preciso um encontro (ou reencontro) com Paulo Freire.

As leituras deste autor apontam como tarefa fundamental da alfabetização a radicalização do princípio a leitura de mundo precede e acompanha a leitura da palavra, entendendo que tem sentido ler e escrever se esse conhecimento possibilita uma compreensão maior da sociedade em que se vive e das estratégias das quais se pode lançar mão para torná-la melhor.

A concepção de alfabetização com a qual trabalhamos, portanto, tem um sentido amplo e não pode desvincular-se de questões tais como: Por quê? Para quê? Em que condições? De acordo com essa concepção defendemos que alfabetizar não se limita a ensinar técnicas de decifração e cópia. Alfabetizar implica criar condições para que as crianças ou adultos não-alfabetizados, hoje 16 milhões, o que representa 13,3\% da população, possam apropriar-se da linguagem escrita, percebendo-a também como mais uma forma de compreensão e intervenção na realidade.

Compreender o aprendizado da língua escrita como um processo linear, cumulativo, hierarquizado - concepção que fundamenta grande parte das cartilhas - representa, na verdade, uma visão simplificadora do 
processo de aprender a ler e a escrever que desintegra a complexidade do real, como explica Morin (1990), na medida em que a correspondência grafo-sonora não garante a compreensão do escrito. Ou seja, aprender a ler e a escrever não é se apropriar de um código de transcrição sonora. Pressupõe uma construção conceitual realizada pelos sujeitos a partir da interação com a própria língua escrita.

O desafio que hoje temos na escola é o de ver a leitura como algo mais que apenas soletrar a escrita, e vermos na escrita algo mais que a transcrição da fala. É preciso que nós, professores e professoras, nos apropriemos de referenciais teóricos que nos ajudem a olhar e ver de forma ampliada o processo de alfabetização.

O desafio é conseguir ver com olhos menos reducionistas a alfabetização, olhos que tragam à luz os saberes que alunos e alunas constroem sobre a escrita e a leitura, olhos que consigam tencionar as verdades construídas pela escola ao longo do tempo. Olhos que possam ver para além do aparente, olhos que desconfiem de crenças e paradigmas.

Ler as produções infantis buscando o que há de saberes escondidos é necessidade não apenas pedagógica, mas também política.

Quando estamos dispostos a ouvir nossos interlocutores, os nossos alunos, levando em conta seus saberes e expectativas, e rompemos com as crenças e verdades já estabelecidas e ousamos mais. Para romper com modelos pré-estabelecidos do que seja ensinar, especialmente do que seja ensinar a ler e escrever é preciso coragem, ousadia e intuição.

Quando olhamos os lugares na escola onde o controle exercido pelo método alfabetizador sobre o processo de aprendizagem dos alunos e alunas é menor, como no recreio, podemos presenciar interessantes discussões.

Vemos muitas vezes crianças discutirem, levantando e negociando hipóteses sobre o que estaria escrito nas revistas e álbuns de figurinhas que levam para o pátio. Em outro momento podemos presenciar alunos buscando decifrar palavras contidas nas embalagens de produtos que trazem 
de casa. Em outras ocasiões ainda, podemos ver estudantes tentando adivinhar palavras escritas nos murais e nas paredes do colégio, ou mesmo brincando de escrever com giz no chão da escola. Em todas essas ocasiões o que vemos é o desafio de ler e escrever para além do ensinado pela escola. E assim, nos perguntamos: por que as escritas reais, cotidianas, presentes no mundo, mobilizam tanto a atenção dos pequenos, já que não são palavras com as quais as crianças estão se deparando no espaço da sala, já que não estão no rol das palavras trabalhadas pela professora em aula?

Ao contrário do que se pensou até há pouco tempo, as crianças se permitem investigar para além do que a escola lhes oferece como conteúdos escolares. As crianças não pedem permissão para aprender, vão exercendo seu direito à curiosidade, deixando-se levar pelo exercício do pensamento. Deixam-se envolver pelo movimento de necessidade da descoberta, mesmo que rodeada de incertezas e caos. Mas como já nos ensinara Prigogine (1997), de um caos, novas organizações surgem, pois que ordem não é o oposto do caos, mas seu elemento constitutivo. Caos/ordem, certeza/incerteza - como faces da mesma e única moeda.

$\mathrm{Na}$ sala de aula a professora tem a ilusão de que é a cartilha quem melhor e mais eficientemente guiará o processo alfabetizador do seu aluno. A professora sente-se segura com este material, afinal, se não der certo, $a$ culpa será da cartilha e do método, dizem muitas professoras.

Fora da sala (e muitas vezes dentro) as crianças mostram que podem mais, que querem mais, que sabem mais. E na sala, também. Mas é preciso, segundo e seguindo o método alfabetizador, percorrer passo a passo o mapa previamente traçado, dando um e somente um passo por vez. Dentro da sala é preciso fazer somente dentro do permitido e estipulado pela autora do livro didático. Os alunos e alunas percebem o jogo que a escola e o método didático querem que seja construído. E dele fazem parte algumas vezes ou, outras tantas, o subvertem - como nas situações de leitura e escrita no recreio. 
Inúmeras vezes, porém, incompreendidas em seus saberes e por não se "adaptarem" às informações e/ou metodologia oferecidas pela escola, muitas crianças "desistem" e assumem como sua a incapacidade de aprender a ler e a escrever.

Para romper com essa concepção de ensino e aprendizagem é preciso perscrutar o cotidiano das salas de aula à procura de pistas, indícios e sinais (GINZBURG, 1991), que possam revelar o que muitas vezes permanece invisível aos olhos da escola: os processos e estratégias de leitura e escrita utilizadas por seus alunos e alunas, reveladores de múltiplas e originais formas de buscar caminhos para aprender.

Por outro lado, é preciso buscar igualmente nas diferentes respostas dadas pelas professoras ao desafio de alfabetizar, práticas mais potencializadoras, já que entendemos o cotidiano escolar como um espaçotempo não apenas da reprodução e do consumo, mas também da produção de novos saberes.

\section{Uma cena do cotidiano escolar: quais saberes trazem as crianças para a escola? Quais dilemas enfrentam as professoras?}

\section{Prof ${ }^{a}$. - Para quê serve o jornal?}

Gabriel - Para saber o que acontece nos lugares que a gente ainda não foi.

Lucas - Pra ler as historinhas.

Tatiana - Pra ver nossos vizinhos quando eles morrem de tiro.

O breve diálogo na rodinha entre a professora de uma escola de educação infantil pública e suas crianças, nos ajuda a refletir sobre os desafios vividos no cotidiano escolar. 
Diante de uma pergunta, que do ponto de vista adulto pode parecer simples e até óbvia — Para quê serve o jornal? — múltiplos caminhos são anunciados, colocando a professora frente à complexidade da prática alfabetizadora.

Em comum nas respostas das crianças está o reconhecimento da função social do jornal. Todas não só reconhecem o jornal como um veículo de informações, como também revelam uma intimidade maior com esse artefato cultural, à medida que remetem aos diferentes cadernos que o compõem: para uma o caderno de viagem com as notícias dos diferentes lugares, para outra o caderno infantil com os jogos e as historinhas, para a terceira um retrato de seu cotidiano mais próximo: o caderno policial. Se buscássemos as falas de outras crianças, encontraríamos como funções do jornal certamente outras respostas: para algumas o jornal poderia servir para embrulhar coisas, para outras, talvez, serviria para esquentar-se do frio. $\mathrm{O}$ desafio que vivemos na escola é entendermos como legítimas as respostas dos nossos alunos, respostas que expressam sua cultura, seu modo de ver a atuar no mundo. O desafio que enfrenta a professora alfabetizadora é incorporar a cultura de seus alunos, muitas vezes diferente da que possui ou valoriza, como base de sua prática pedagógica diária.

Mas como alfabetizar a partir da "realidade vivida" que as crianças trazem para a sala de aula se essa realidade é sempre múltipla e heterogênea?

Questões como essa vão se tornando mais freqüentes no cotidiano escolar, quando as professoras alfabetizadoras, no esforço de incorporar outros portadores de texto no processo de alfabetização, além da cartilha, se deparam com a multiplicidade de experiências vividas pelas crianças com o mundo da leitura.

Possibilitar que as experiências extra-escolares das crianças com a leitura e a escrita apareçam no cotidiano escolar, desafia a professora a romper com vários pressupostos da metodologia que utiliza em sala. A 
relação entre o que é simples e o que é complexo é um deles. O que para a professora pode ser simples, ou representar a ordem, como as vogais ou os ditongos que iniciam o processo de alfabetização, por exemplo, para as crianças pode ser complicado e representar uma desordem, na medida em que não tem sentido para elas, pois não servem para contar uma história, escrever uma notícia ou colocar no jornal o nome do vizinho que foi atingido pelo tiro.

Para que possam aprender a ler e a escrever, a partir de uma metodologia tradicional, as crianças terão que abrir mão do que já sabem sobre a língua escrita, ou mesmo do que esperam que a aprendizagem da leitura e da escrita lhes proporcionem, para se enquadrarem no ritmo esperado, subordinado hegemonicamente à cópia e a repetição das palavraschaves ou das famílias silábicas.

Contudo, a complexidade, que caracteriza o cotidiano escolar, inúmeras vezes, abre caminho para que crianças e professoras rompam com uma perspectiva mecanicista do processo ensino-aprendizagem da leitura e da escrita, experimentando novas relações com o conhecimento.

Este foi o caminho trilhado por nossa professora que diante dos conhecimentos revelados pelas crianças ao seu questionamento sobre as funções do jornal, foi em frente, propôs à turma que produzissem o seu próprio jornal, possibilitando, dessa forma, que as crianças colocassem em jogo, naquele momento, também os seus conhecimentos sobre a escrita.

Tendo como referência uma concepção dialógica do processo ensino-aprendizagem, Freire apontava que a alfabetização implica “[...] não uma memorização visual e uma mecânica de sentenças, de palavras, de sílabas, desgarradas de um universo existencial - coisas mortas ou semimortas - mas numa atitude de criação e recriação." (FREIRE, 1978, p. 111). Por implicar numa atitude de criação e de recriação, a alfabetização não pode ser feita de cima para baixo, como uma doação ou uma imposição, 
mas pelo próprio sujeito, com a colaboração do educador e dos demais colegas.

Daí a importância do diálogo entre a professora alfabetizadora e as crianças e entre as próprias crianças, de forma que possam emergir e interagir na sala de aula, modos de pensar, viver, agir e sentir que encontrem no processo de alfabetização um canal de expressão e um instrumento de intervenção em seu contexto.

Pensar a alfabetização a partir dos conteúdos vivos que permeiam a sala de aula - numa perspectiva freiriana, na qual a leitura e a escrita da palavra é um instrumento de ampliação da leitura de mundo dos sujeitos alfabetizandos - e não apenas a partir do estudo da estrutura da língua, abre espaço para que novos caminhos possam ser construídos na prática alfabetizadora.

\section{Como alfabetizar numa perspectiva emancipatória?}

A leitura de Paulo Freire permite afirmar que o ponto de partida para a construção de ambientes alfabetizadores favoráveis à aprendizagem das crianças das classes populares precisa tomar como base a experiência vivida por essas crianças fora da escola, sintetizada na relação leitura de mundo/leitura da palavra.

[...] não podemos deixar de lado, desprezado como algo imprestável, o que educandos, sejam crianças chegando à escola ou jovens e adultos a centros de educação popular, trazem consigo de compreensão do mundo, nas mais variadas dimensões de sua prática na prática social de que fazem parte. Sua fala, sua forma de contar, de calcular, seus saberes em torno do chamado outro mundo, sua religiosidade, seus saberes em torno da saúde, do corpo, da sexualidade, da vida, da morte, da força dos santos, dos conjuros. (FREIRE, 1992, p. 85-86)

É a partir dessa relação leitura de mundo/leitura da palavra que o processo de ensinar a ler e a escrever pode se tornar um instrumento que possibilite professoras e crianças a escrever e dizer suas próprias palavras e, 
quem sabe, dessa forma, contribuir, também, para fortalecer a luta por uma sociedade mais igualitária.

Organizar o ensino procurando criar condições para a apropriação da linguagem escrita como um instrumento de compreensão e intervenção na realidade, implica, em primeiro lugar, a possibilidade de oferecer experiências que tenham relevância e significado para a vida da criança, que torne a leitura e escrita uma necessidade para ela.

Para isso é preciso que as crianças sejam constantemente desafiadas, através de situações diversificadas e significativas, a refletirem sobre o seu próprio processo de construção de conhecimento, experimentando/exercitando a escrita - escrevendo, e da mesma forma, experimentando/exercitando a leitura - lendo. Contrapondo, dessa forma, ao uso escolarizado que se faz da escrita, um uso social que de fato possibilite a apropriação dessa linguagem.

Não se trata de propor à professora um novo método de alfabetização ou definir as etapas de uma nova metodologia a ser seguida à risca, porém, trata-se de enfatizar a importância da reflexão coletiva e do permanente preparar-se como condições básicas para o fortalecimento de uma prática alfabetizadora comprometida com as crianças das classes populares.

\section{Referências bibliográficas}

FREIRE, Paulo (1978). A educação como prática da liberdade. 8. ed. São Paulo: Paz e Terra.

(1992). Pedagogia da esperança: um reencontro com a pedagogia do oprimido. 2. ed. São Paulo: Paz e Terra.

GARCIA, Regina Leite (Org.) (2001). Novos olhares sobre alfabetização. São Paulo: Cortez.

GINZBURG, Carlo (1991). Mitos, emblemas e sinais. São Paulo: Companhia das Letras. 
MORIN, Edgar (1997). Introdução ao pensamento complexo. Lisboa: Instituto Piaget.

PRIGOGINE, Ilya; STENGERS, Isabelle (1997). A Nova aliança. Metamorfose da ciência. Brasília: Editora UNB.

\section{Autoras}

\section{Jacqueline de Fátima dos Santos Morais}

Doutorada em educação. Professora adjunta na Universidade do Estado do Rio de Janeiro - Faculdade de Formação de Professores.

Endereço profissional:

Rua Dr. Francisco Portela, 794 - Paraíso - São Gonçalo - RJ

Tel.: (21) 2604-3232

Endereço residencial:

Rua Intendente Cunha Menezes, 257 - ap. 304 - Méier - RJ - 20720-060

Tel.: (21) 2269-3867

jacquelinemorais@hotmail.com

\section{Mairce da Silva Araújo}

Doutorada em educação. Professora adjunta na Universidade do Estado do Rio de Janeiro - Faculdade de Formação de Professores.

Endereço profissional:

Rua Dr. Francisco Portela, 794 - Paraíso - São Gonçalo - RJ

Fone: (21) 2604-3232

Endereço residencial:

Rua Ministro Viveiros de Castro, 145/202 - Copacabana - RJ - 02122-010

Fone: (21) 2543-3629

mairce@hotmail.com

\section{Como citar este artigo:}

MORAIS, Jacqueline de Fátima dos Santos e ARAÚJO, Mairce da Silva. Alfabetização: desafios da prática alfabetizadora. Revista ACOALFAplp: Acolhendo a Alfabetização nos Países de Língua portuguesa, São Paulo, ano 2, n. 3, 2007. Disponível em: <http://www.mocambras.org> e ou <http://www.acoalfaplp.org>. Publicado em: setembro 2007. 